\title{
Usefulness of BK virus-specific interferon- $\gamma$ enzyme-linked immunospot assay for predicting the outcome of BK virus infection in kidney
} transplant recipients

\author{
Hyunjoo Bae ${ }^{1,{ }^{*}}$, Do Hyun Na ${ }^{2,3,}$, Ji-Yeun Chang ${ }^{2,3}$, Ki Hyun Park ${ }^{1}$, Ji Won Min ${ }^{2,4}$, Eun Jeong Ko $^{2,3}$, \\ Hyeyoung Lee ${ }^{5,6}$, Chul Woo Yang ${ }^{2,3}$, Byung Ha Chung ${ }^{2,3}$, and Eun-Jee Oh ${ }^{5}$
}

\begin{abstract}
${ }^{1}$ Department of Biomedical Science, Graduate School, College of Medicine, The Catholic University of Korea, Seoul; ${ }^{2}$ Transplant Research Center, ${ }^{3}$ Division of Nephrology, Department of Internal Medicine, Seoul St. Mary's Hospital, College of Medicine, The Catholic University of Korea, Seoul; ${ }^{4}$ Division of Nephrology, Department of Internal Medicine, Bucheon St. Mary's Hospital, College of Medicine, The Catholic University of Korea, Bucheon; ${ }^{5}$ Department of Laboratory Medicine, Seoul St. Mary's Hospital, College of Medicine, The Catholic University of Korea, Seoul; ${ }^{6}$ Department of Laboratory Medicine, International St. Mary's Hospital, Catholic Kwandong University College of Medicine, Incheon, Korea
\end{abstract}

\section{Received: October 16, 2019 Revised : November 13, 2019 Accepted: November 15, 2019}

\section{Correspondence to}

Eun-Jee Oh, M.D.

Department of Laboratory Medicine, Seoul St. Mary's Hospital, College of Medicine, The Catholic University of Korea, 222 Banpo-daero, Seocho-gu, Seoul 06591, Korea

Tel: $+82-2-2258-1641$

Fax: +82-2-2258-1719

E-mail: ejoh@catholic.ac.kr https://orcid.org/0000-00015870-915X

*These authors contributed equally to this work.

Background/Aims: To investigate if BK virus (BKV)-specific T cell immunity measured by an interferon- $\gamma$ enzyme-linked immunospot (ELISPOT) assay can predict the outcome of BK virus infection in kidney transplant recipients (KTRs). Methods: We included $68 \mathrm{KTR}$ s with different viremia status (no viremia [ $=17]$, BK viremia $[\mathrm{n}=27]$, and cleared viremia $[\mathrm{n}=24]$ ) and 44 healthy controls (HCs). The BK viremia group was divided into controller ( $<3$ months) and noncontroller ( $>3$ months) according to sustained duration of BKV infection. We compared BKV-ELISPOT results against five BKV peptides (large tumor antigen [LT], St, VP1-3).

Results: BKV-ELISPOT results were higher in three KTRs groups with different BKV infection status than the HCs group $(p<0.05)$. In KTR groups, they were higher in cleared viremia group than no viremia or BK viremia group. Within the BK viremia group, controller group had higher LT-ELISPOT results compared to noncontroller group $(p=0.032)$. Also, KTRs without BK virus-associated nephropathy (BKVN) had higher LT, St, VP1, and VP2-ELISPOT results than those with $\operatorname{BKVN}(p<0.05)$.

Conclusions: BKV-ELISPOT assay may be effective in predicting clinical outcomes of BKV infection in terms of clearance of BK virus and development of BKVN.

Keywords: BK virus; Kidney transplantation; Viremia; BK polyomavirus-associated nephropathy; Enzyme-linked immunospot assay

\section{INTRODUCTION}

BK virus-associated nephropathy (BKVN) has emerged as an important factor of graft kidney prognosis in kidney transplant recipients (KTRs) along with introduction of the combination of tac- rolimus and mycophenolate mofetil (MMF) [1-3]. The nature of polyomavirus BK (BKV), which has latency and high seroprevalence rate of $60 \%$ to $90 \%$ in adults, results in viral reactivation and replication with intensive immunosuppressive therapy $[4,5]$. It is con- 
sidered that the short-term prognosis of patients with $\mathrm{BKV}$ infection is good, but the long-term prognosis is poor especially with concurrent rejection [3]. Because of the lack of effective antiviral treatment, only regular monitoring of BKV-reactivation and timely reduction of immunosuppression are strongly recommended $[1,6-8]$. Although immunosuppression reduction is an effective treatment of BK viremia, it can increase the risk of de novo donor-specific antibodies, graft rejection [9]. The currently used BKV infection monitoring method is based on BKV real-time quantitative polymerase chain reaction (RT-qPCR) for quantification of BKV-DNA in serum or urine [4]. However, RT-qPCR of BKV-DNA has limitations, including relatively low positive predictive value of $43 \%$ to $82 \%$ in identifying patients at risk for BKVN $[10,11]$. For this reasons, clinicians have difficulty deciding treatment for BKV infection based on risk of rejection and BKVN. Therefore, improved predictive marker for clearance of BKV and development of BKVN is needed to plan optimal therapeutic strategies.

It is well-known that the clinical course of opportunistic viral infection depends on efficacy of patient's immune response to the virus [12-14]. In addition, several studies have suggested that control of BKV replication is correlated with BKV-specific cellular immunity [15-18]. What is the best immunological biomarker to BKV-specific immunity is still debated, BKV-specific interferon- $\gamma$ enzyme-linked immunospot (BKV-ELISPOT) assays are relatively high throughput, sensitive method for monitoring cellular responses by detecting antigen-specific T cells activation [19]. So, there are many studies tried to establish the clinical significance of BKV-ELISPOT [15,18,20-22].

Previous studies may have suggested BKV-ELISPOT results are associated with control and protection from BKV replication and serve as a marker of BKV replication $[15,16,18,20-23]$. However, previous studies were focused on association of BKV-ELISPOT with occurrence risk of BKV infection. Some studies focused on clinical outcome had relatively small number of patients $[20,22]$. One study showed that nine patients of cleared viremia had higher BKV-ELISPOT results than healthy controls (HCs) and KTRs with BK viremia [20]. Schachtner et al. [15] suggested that the development of BKV-specific T cells corresponds with recovery from BKVN analyzing the ELISPOT results of seven patients with BKVN and 11 patients with self-limited BKV-reactivation. In this

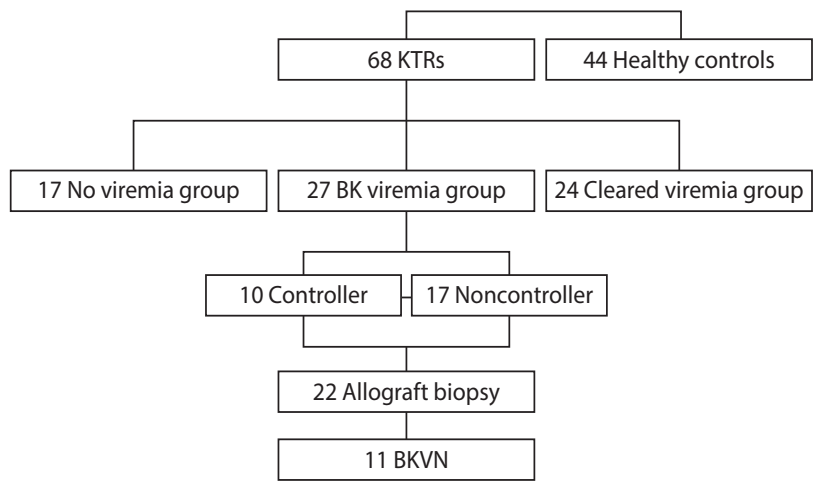

Figure 1. Distribution of kidney transplant recipients in this study. KTR, kidney transplant recipient; BKVN, BK virus-associated nephropathy.

regard, the purpose of this study was to investigate if the post-transplant BKV-specific $\mathrm{T}$ cell monitoring using BKV-ELISPOT assay could predict clinical outcomes of BKV infection, especially focused on clearance of BKV and development of BKVN.

\section{METHODS}

\section{Defining patient cohort and measuring BKV-specific immunity}

Sixty-eight KTRs, who agreed to donate peripheral blood at the time of measuring BKV-DNA using RT-qPCR, were included in this study. All participants provided written informed consent in accordance with the Declaration of Helsinki. This study was approved by the Institutional Review Board at Seoul St. Mary's Hospital (KC16TISIo70o). They were divided into three groups according to their viremia status before and at enrollment, evaluated by routine screening for BKV in our transplant center [24]; (1) no viremia $(\mathrm{n}=17),(2) \mathrm{BK}$ viremia $(n=27)$, and $(3)$ cleared viremia $(n=24)$. The no viremia group consisted of patients with no evidence of viral replication at post-transplant routine screening using blood BKV-DNA PCR and for the next 6 months after enrollment. The BK viremia group was comprised of patients who showed significant blood BKV-DNA at the time of the BKV-ELISPOT test, irrespective of results before enrollment. The significant blood BKV-DNA was defined as the value higher than 4 log copies/mL according to our own and also other group's previous studies 
$[24,25]$. In the BK viremia group, we performed subgroup analysis according to the clinical course of BKV infection; the controller group who showed clearance of BK viremia within 3 months, and the noncontroller group, who had persistent viremia up to 6 months after diagnosis of BKV infection (Fig. 1) [26]. Clearance of BK viremia indicates that blood BKV PCR is less than 500 copies/ $\mathrm{mL}$. The cleared viremia group included patients who had no viremia at the time of enrollment, but experienced viremia previously. We also included $44 \mathrm{HCs}$.

\section{Investigation of BKV replication and BKV-associated nephropathy}

BKV-DNA quantification in whole blood was performed by RT TaqMan PCR kit (Applied Biosystems, Foster City, CA, USA) to detect target viral capsid protein (VP-1) gene using an ABI PRISM 7000 real-time PCR system (Applied Biosystems). We performed BKV monitoring and preemptive immune suppressant reduction according to our transplant center's protocol [24]. Briefly, plasma BKV PCR was performed at 1, 3, 6, 9,12 months after transplantation, and once a year afterward or when allograft dysfunction was detected. We defined significant BK viremia as detection of BKV (> 4 $\log$ copies $/ \mathrm{mL}$ ) in the blood sample [24,25]. When significant BK viremia was detected, we discontinued MMF and monitored BKV RT-qPCR every month until BK viremia disappeared. When $\mathrm{BK}$ viremia was sustained after one month, we performed allograft biopsy, and the dose of calcineurin inhibitor (CNI) was reduced by $20 \%$, and also started leflunomide [24]. Diagnosis of BKVN was confirmed when the following criteria were met: (1) typical histological features suggestive of BKVN such as presence of intra-nuclear viral inclusions, (2) positive SV40 T by immunoperoxidase staining, and (3) detection of BKV replication in at least one test among urine cytology, urine PCR, or plasma PCR [27].

\section{BKV-specific $T$ cell ELISPOT assay}

BK virus has double-stranded DNA genomes which include two early enzymatic proteins and three late structural proteins. The early proteins are the large tumor antigen (LT) and the small tumor antigen (St). These T antigens are responsible for cell immortalization and latency. Late structural proteins consist of viral capsid: $\mathrm{VP}_{1}, \mathrm{VP}_{2}$, and $\mathrm{VP}_{3}[28,29]$. We measured $\mathrm{T}$ cell respons- es to each of the five proteins using ELISPOT assay. We used a commercial (Human interferon $\gamma$ [IFN- $\gamma$ ] ELISPOT Ready-SET-Go, eBioscience, San Diego, CA, USA), 96-well ELISPOT plates (Millipore, Cat. No. MAIPS4510) were washed and coated overnight at $4^{\circ} \mathrm{C}$ with $100 \mu \mathrm{L} /$ well of a mouse monoclonal anti-human IFN- $\gamma$ capture antibody diluted in ELISPOT coating buffer (reconstitute powder to $1 \mathrm{~L}$ in $\mathrm{dH}_{2} \mathrm{O}$ ). And then, coating antibody was aspirated from plate. Plates were washed with $200 \mu \mathrm{L} /$ well of sterile ELISPOT coating buffer and blocked with $200 \mu \mathrm{L} /$ well of complete RPMI-1640 (with Fetal Bovine Serum and $1 \%$ Penicillin/Streptomycin/L-Gutamine) at room temperature for 1 hour. Peripheral blood mononuclear cells $(\mathrm{PBMCs})\left(3 \times 10^{5}\right.$ cells/well) were stimulated with phorbol 12-myristate 13-acetate (PMA)/ionomycin (positive control), complete media (negative control) and BKV peptide $\left(1 \mu \mathrm{g} / \mathrm{mL}\right.$ of $\mathrm{VP}_{1}, \mathrm{VP}_{2}, \mathrm{VP}_{3}, \mathrm{LT}$, and St, JPT, Peptides Technologies, Berlin, Germany) diluted in complete RPMI-1640 to appropriate wells at $100 \mu \mathrm{L} /$ well in $5 \% \mathrm{CO}_{2}$ humidified incubator, at $37^{\circ} \mathrm{C}$ for 24 hours. Plates were washed with ELISPOT wash buffer $(1 \times$ PBS, with $0.05 \%$ Tween-20) and diluted by biotinylated detection antibody (Anti-Human IFN gamma Biotin) in Assay Diluent $\left(1 \mathrm{X}\right.$ in $\left.\mathrm{dH}_{2} \mathrm{O}\right)$ with $100 \mu \mathrm{L} /$ well of detection antibody solution. Incubate at room temperature for $\mathbf{2}$ hours. Next, plates were washed with ELISPOT wash buffer, diluted by Avidin-HRP reagent in Assay Diluent with $100 \mu \mathrm{L} /$ well of Avidin-HRP solution and incubate at room temperature for 45 minutes. Then, washed with ELISPOT wash buffer and two times with $1 \times$ PBS (no Tween-20). Plates were developed at room temperature for 30 minutes with 100 $\mu \mathrm{L} /$ well of freshly-prepared AEC (3-amino-9-ethyl carbazole) substrate solution and stopped the substrate reaction by washing well with $200 \mu \mathrm{L} /$ well of distilled water. Air-drying the plate, resulting spots were counted using a computer-assisted ELISPOT image analyzer (Cellular Technologies Ltd., Cleveland, OH, USA). Results were calculated as mean values of spots $/ 3 \times 10^{5}$ cells PBMC based on duplicate or triplicate measurements after subtracting the response of negative control wells.

\section{Assessment of clinical outcomes of BKV infection}

First, we compared results of BKV-ELISPOT among the four groups (HCs $[\mathrm{n}=44]$ and the three KTRs: no viremia $[n=17]$, BK viremia $[n=27]$, cleared viremia $[n=24]$ ). Second, we investigated if the BKV-ELISPOT results 
Table 1. Baseline characteristics of kidney transplant recipients

\begin{tabular}{lccc}
\hline \multirow{2}{*}{ Characteristic } & \multicolumn{3}{c}{ BK viremia status } \\
\cline { 2 - 4 } Age, yr & No viremia $(\mathrm{n}=17)$ & BK viremia $(\mathrm{n}=27)$ & Cleared viremia $(\mathrm{n}=24)$ \\
Male sex & $42.1 \pm 10.6$ & $55.4 \pm 11.4^{\mathrm{a}}$ & $48.0 \pm 13.8$ \\
Deceased donor KT & $7(41.2)$ & $19(70.4)$ & $15(62.5)$ \\
ABOi KT & $3(17.6)$ & $4(44.4)$ & $5(20.8)$ \\
HLA mismatch number & $5(29.4)$ & $4.3 \pm 1.6^{\mathrm{a}, \mathrm{b}}$ & $3(12.5)$ \\
Highly sensitized & $2.6 \pm 1.5$ & $8(29.6)$ & $3.3 \pm 1.5$ \\
Induction with ATG & $3(17.6)$ & $9(33.3)$ & $3(12.5)$ \\
Immunosuppressants & $2(11.8)$ & & $3(12.5)$ \\
$\quad$ CNI/MPA/PD & & $26(96.2)^{\mathrm{b}}$ & \\
$\quad$ CNI/MPA & $13(76.5)$ & 0 & $16(66.6)$ \\
$\quad$ CNI/PD & $1(5.9)$ & $1(3.7)$ & 0 \\
Serum tacrolimus level, ng/mL & $2(11.8)$ & $6.4 \pm 2.9^{\mathrm{b}}$ & $8(33.3)$ \\
Time interval from KT to ELISPOT test, mon & $5.5 \pm 2.3$ & $11.1(3.8-22.9)^{\mathrm{a}, \mathrm{b}}$ & $3.3 \pm 1.5$ \\
Serum creatinine, mg/dL & $2.8(2.5-6.6)$ & $1.5(1.4-2.2)^{\mathrm{a}}$ & $1.5(1.1-1.6)$ \\
Peak BKV PCR titer, log copies/mL & $1.2(0.9-1.3)$ & $5.4 \pm 1.2^{\mathrm{b}}$ & $4.3 \pm 0.9$ \\
\hline
\end{tabular}

Values are presented as mean $\pm \mathrm{SD}$, number (\%), or median (interquartile range).

KT, kidney transplantation; ABOi, ABO incompatible; HLA, human leukocyte antigen; ATG, anti-thymocyte globulin; CNI, calcineurin inhibitor; MPA, mycophenolic acid; PD, prednisolone; ELISPOT, enzyme-linked immunospot; PCR, polymerase chain reaction.

${ }^{\mathrm{a}} \mathrm{A} p<0.05$ when compared to no viremia group.

${ }^{\mathrm{b}} \mathrm{A} p<0.05$ when compared to cleared viremia group.

can predict clearance of BKV infection in the BK viremia group. We compared ELISPOT results at diagnosis of BK viremia between of the controller $(n=10)$ and the noncontroller $(n=17)$ groups. In the BK viremia group, 11 patients were diagnosed as BKVN, and we compared ELISPOT results between the BKVN group and no BKVN group.

\section{Statistical analysis}

Statistical analyses were performed using the SPSS software version 24.0 (IBM Co., Armonk, NY, USA). Categorical variables were compared by Pearson's chisquare test or Fisher's exact test. Continuous variables were compared using Student's $t$ test or Mann-Whitney $U$ test between two groups, and we used one-way analysis of variance test or Kruskal-Wallis test to compare continuous variables among KTRs according to viremia status. For non-parametric variables, transformation to ranking variables was used. The relationship between two parameters was assessed by Spearman's correlation rank test. All tests were two-tailed, and the results were considered significant at $p<0.05$.

\section{RESULTS}

\section{Baseline characteristics of kidney transplant recipients}

Table 1 shows the characteristics of the KTRs in this study. Mean age of the KT'Rs was $50.4 \pm 13.5$ years and $66 \%$ of the study group was male. Comparing KTRs with different viremia status, age of recipients, human leukocyte antigen (HLA) mismatch number and serum creatinine levels were higher in the BK viremia group compared to those in the no viremia group $(p<0.05)$. There was no difference in percentage of deceased donor-KTs and the induction therapy with anti-thymocyte globulin (ATG) among the three groups $(p>0.05)$. Serum tacrolimus trough level at the time of BKV-ELISPOT assays, time interval from kidney transplantation to BKV-ELISPOT 
Table 2. Comparison of baseline characteristics between controller and noncontroller in BK viremia group

\begin{tabular}{|c|c|c|c|}
\hline \multirow{2}{*}{ Characteristic } & \multicolumn{2}{|c|}{$\mathrm{BK}$ viremia group } & \multirow{2}{*}{$p$ value } \\
\hline & Controller $(\mathrm{n}=10)$ & Noncontroller $(\mathrm{n}=17)$ & \\
\hline Age, yr & $48.4 \pm 11.3$ & $59 \cdot 5 \pm 9.5$ & 0.010 \\
\hline Male sex & $7(70.0)$ & $12(70.5)$ & 0.334 \\
\hline Deceased donor KT & $3(30.0)$ & $10(58.8)$ & 0.116 \\
\hline Class PRA I & $18.3 \pm 33.0$ & $16.1 \pm 35.4$ & 0.877 \\
\hline Class PRA II & $18 \pm 38.2$ & $22.0 \pm 39.4$ & 0.796 \\
\hline HLA mismatch number & $3 \cdot 3 \pm 2.2$ & $4 \cdot 5 \pm 1.1$ & 0.061 \\
\hline ABO incompatibility & $2(20.0)$ & $2(11.7)$ & 0.348 \\
\hline Induction with ATG & $1(10.0)$ & $9(52.9)$ & 0.028 \\
\hline \multicolumn{4}{|l|}{ Immunosuppressant } \\
\hline Tacrolimus/MPA/PD & $9(90)$ & $17(100)$ & 0.370 \\
\hline Tacrolimus/PD & $1(10)$ & O & 0.370 \\
\hline Serum tacrolimus level, ng/mL & $5.7 \pm 1.9$ & $6.9 \pm 3.3$ & 0.317 \\
\hline Concurrent rejection & $5(50.0)$ & $3(17.6)$ & 0.077 \\
\hline Antibody-mediated rejection & $1(10.0)$ & $2(11.7)$ & 0.464 \\
\hline T cell-mediated rejection & $4(40.0)$ & $1(5.8)$ & 0.044 \\
\hline de novo DSA & $1(10.0)$ & $1(5.8)$ & 0.484 \\
\hline EBV coinfection & o & $4(23 \cdot 5)$ & 0.135 \\
\hline CMV coinfection & $4(40.0)$ & $6(35 \cdot 2)$ & 0.308 \\
\hline \multicolumn{4}{|l|}{ Intervention } \\
\hline Withdrawal MPA & $8(80)$ & $17(100)$ & 0.128 \\
\hline Addition leflunomide & $5(50)$ & $14(82.3)$ & 0.077 \\
\hline Reduction tacrolimus & $2(20)$ & $2(11.1)$ & \\
\hline Peak BKV PCR titer, log copies/mL & $4.7 \pm 0.8$ & $5.8 \pm 1.0$ & 0.004 \\
\hline Time interval from KT to ELISPOT test, mon & $3.4(2.7-4.1)$ & $22.9(11.1-32.4)$ & $<0.001$ \\
\hline Time interval from KT to BK viremia, mon & $2.2\left(1.5^{-2.9)}\right.$ & $4.8(2.8-25.9)$ & 0.003 \\
\hline Viremia duration, mon & $1.9(1.1-2.4)$ & $27.8(12-40.3)$ & $<0.001$ \\
\hline Serum creatinine, $\mathrm{mg} / \mathrm{dL}$ & $1.36(1.27-1.49)$ & $2.02\left(1.5^{1-2.68)}\right.$ & 0.050 \\
\hline Incident BKVN & $3(30.0)$ & $8(47 \cdot 0)$ & 0.154 \\
\hline Loss of graft function & $\mathrm{O}$ & $\mathrm{O}$ & 1.000 \\
\hline
\end{tabular}

Values are presented as mean $\pm \mathrm{SD}$, number (\%), or median (interquartile range).

KT, kidney transplantation; PRA, panel reactive antibody; HLA, human leukocyte antigen; ATG, anti-thymocyte globulin; MPA, mycophenolic acid; PD, prednisolone; DSA, donor-specific antibody; EBV, Epstein-Barr virus; CMV, cytomegalovirus; ELISPOT, enzyme-linked immunospot; BKVN, BK virus-associated nephropathy.

assays and peak BKV PCR titer in blood were higher in the BK viremia group compared to the cleared viremia group. The BK viremia group patients had received triple immunosuppressive therapy consisting of a tacrolimus, mycophenolic acid (MPA), and prednisolone (PD) ( $n=26,96.2 \%$ ) before onset of the viremia. Patients who diagnosed with BK viremia changed their maintenance immunosuppressant as followings, MPA withdrawal (n =6), leflunomide addition ( $\mathrm{n}=2)$, MPA withdrawal with leflunomide addition $(\mathrm{n}=17)$, and MPA withdrawal with tacrolimus reduction $(\mathrm{n}=2)$ (Table 2). 

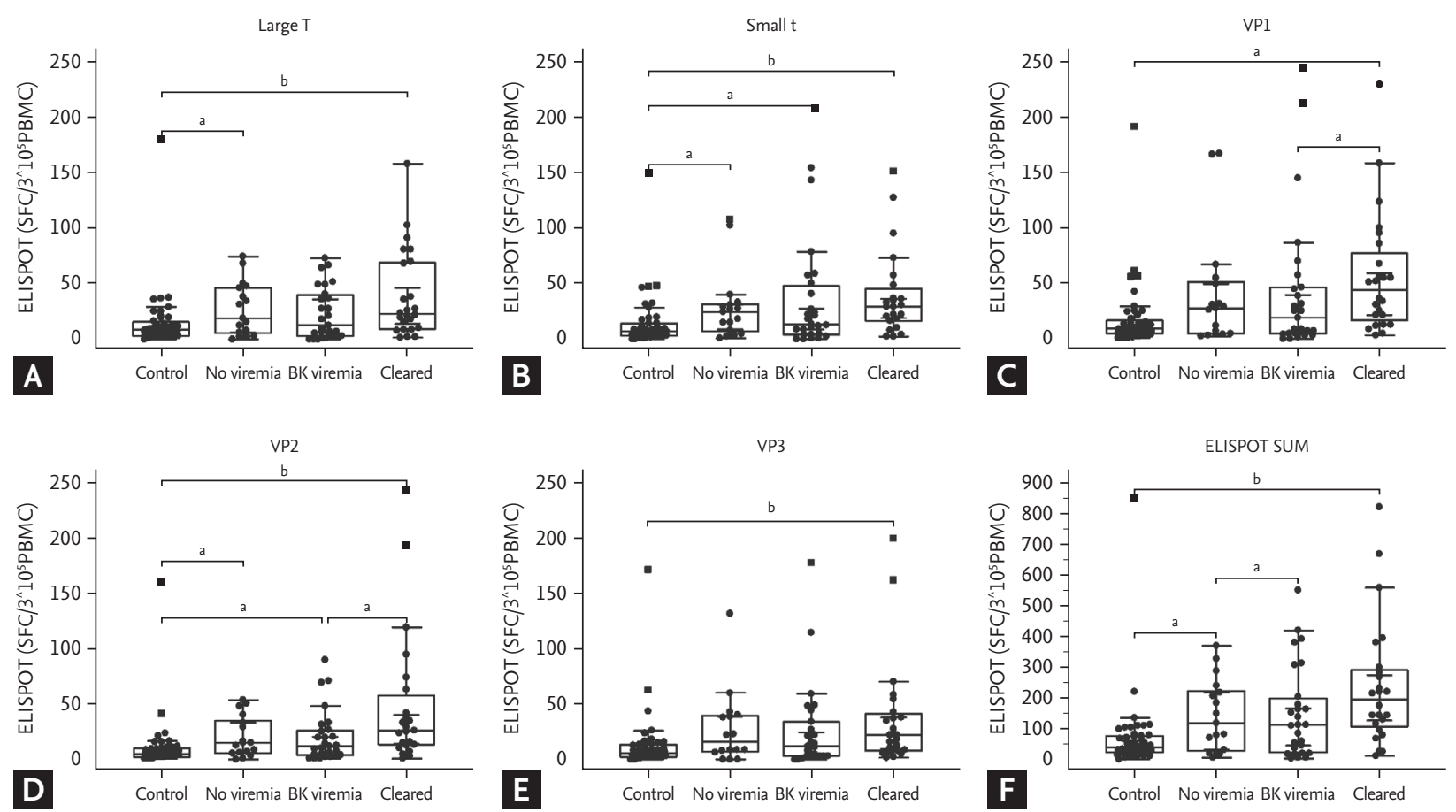

Figure 2. BK virus (BKV) specific interferon $\gamma$ enzyme-linked immunospot (ELISPOT) results of healthy controls and kidney transplant recipients (KTRs) in three groups of no viremia, BK viremia, and cleared viremia. Vertical bars showed the median value of BKV-specific ELISPOT counts in each of the five BKV antigens. (A) In the large T antigen, the spot was significantly higher in the no viremia group and the cleared viremia group than in the control group. (B) In the small $t$ antigen, the spot was significantly higher in all KTR groups than the control group. (C) In the VP1 antigen, the control group had a lower spot score than the cleared viremia group. The BK viremia group was also significantly lower than the cleared viremia group. (D) In the VP2 antigen, the control group was spot-lower than all KTR groups, and the BK viremia group had fewer spot numbers than the cleared viremia group. (E) In the VP3 antigen, the control group had a lower spot than the cleared viremia group. (F) ELISPOT SUM shows the sum of ELISPOT counts against each of five BKV peptides (large tumor antigen [LT], St, VP1, VP2, and $\mathrm{VP}_{3}$ ). SFC, spot forming cell; PBMC, peripheral blood mononuclear cell. ${ }^{\mathrm{a}} \mathrm{p}<0.05$ by Mann-Whitney test. ${ }^{\mathrm{b}} p<0.01$.

\section{Comparison of BKV-specific T cell responses among healthy controls and kidney transplant recipients in three groups}

KTRs had higher BKV-ELISPOT results against all five peptides than HCs $(p<0.05)$. All three KT'Rs group showed significantly higher or higher tendency of ELISPOT results for all five peptides than HCs. Among KTRs with different viremia statuses, we found increasing tendency of ELISPOT results in the no viremia or the cleared viremia group in comparison with the BK viremia group. The BK viremia group had a lower number of spots than the no viremia group but it is not significant. In comparison between the $\mathrm{BK}$ viremia and the cleared viremia group, $\mathrm{VP} 1$ and VP2 ELISPOT results were significantly higher in the cleared group $(p=0.0434$ and $p=0.0245$, respectively)
(Fig. 2). Between the no viremia and the cleared viremia group, no significant difference was detected for all five peptides.

\section{BKV-specific T cell responses in predicting the clinical outcome of BKV infections}

In the BK viremia group, 10 (37.0\%) patients succeeded in BK viral clearance (the controller group) within 3 months, and 17 (63.0\%) patients showed persistent viremia for more than 3 months (the noncontroller group). In the noncontroller group, LT-ELISPOT results were significantly lower $(p=0.033)$ and other ELISPOT results also showed lower tendency compared to the controller group. The controller group had higher ELISPOT SUM which means the sum of each spot count of five BKV peptides (LT, St, VP1, VP2, and $\mathrm{VP}_{3}$ ) than the noncon- 

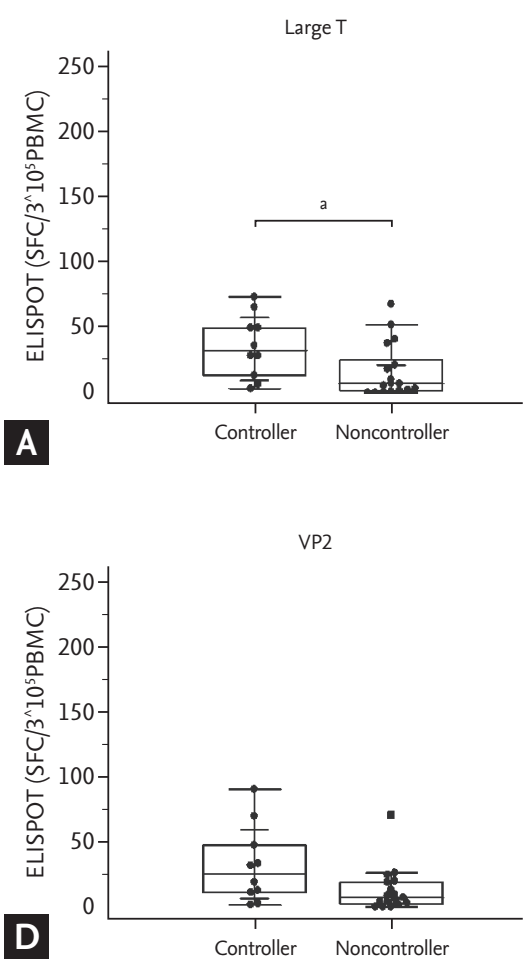
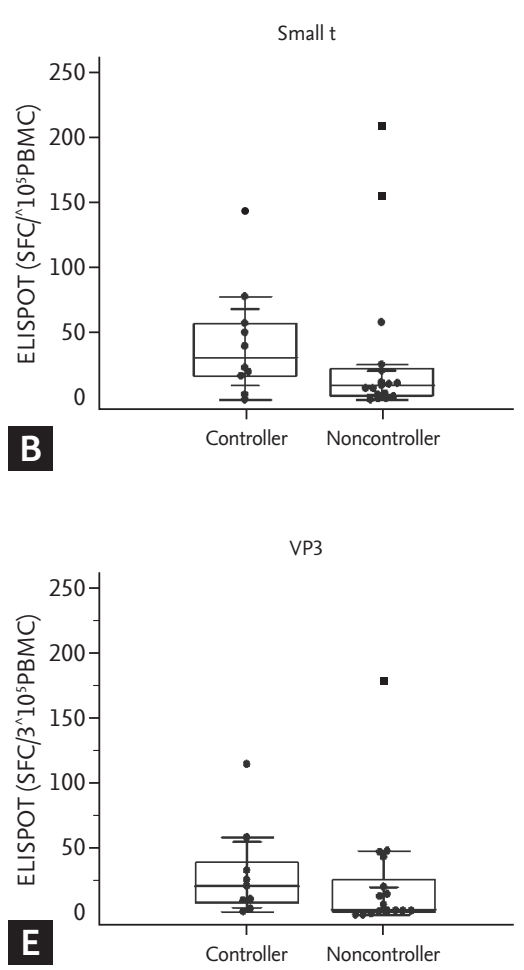
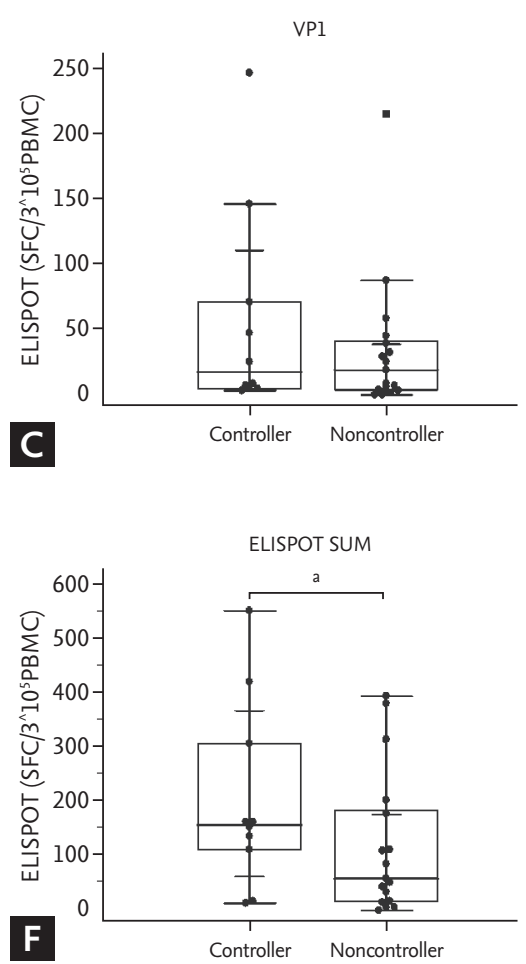

Figure 3. Comparison of BK virus (BKV)-specific interferon $\gamma$ enzyme-linked immunospot (ELISPOT) results between controller and noncontroller in the BK viremia group. Vertical bars showed the median value of BKV-specific ELISPOT counts in each of the five BKV antigens. (A) Controller of the BK viremia group is significantly higher than that of noncontroller in large $\mathrm{T}$ antigen. In the $\mathrm{BK}$ viremia group, controller tends to be spot-higher than noncontroller in the other BKV antigens of (B) small t, (C) VP1, (D) VP2, and (E) VP3. (F) ELISPOT SUM shows the sum of ELISPOT counts against each of five BKV peptides (large tumor antigen [LT], St, VP1, VP2, and VP3). SFC, spot forming cell; PBMC, peripheral blood mononuclear cell. ${ }^{\mathrm{a}} \mathrm{p}<0.05$ by Mann-Whitney test.

troller group $(p=0.0486)$ (Fig. 3). We also investigated if BKV-ELISPOT results can predict the development of BKVN. Of 27 KTRs in the BK viremia group, 22 KTRs received allograft biopsies during 6 months' follow-up, and 11 patients were confirmed as BKVN. The 11 BKVN (+) patients had lower BKV-ELISPOT results for LT, St, $\mathrm{VP} 1, \mathrm{VP}_{2}$ peptides at the time of BK viremia development than $16 \mathrm{BKVN}(-)$ patients in the BK viremia group $(p=0.036, p=0.043, p=0.006$, and $p=0.025$, respectively). ELISPOT SUM at the time of BK viremia was lower in patients with BKVN than those without BKVN $(p=$ 0.0136) (Fig. 4).

\section{DISCUSSION}

This study was conducted on 68 KTRs and 44 HCs to evaluate if the ELISPOT used to measure T cell respons- es could serve as a predictor of post-transplant BKV nephropathy and BKV clearance. We observed that KT'Rs with low levels of BKV-ELISPOT responses showed lower odds of early BKV clearance and also had higher odds of development of BKVN. Our results suggest that the BKV-ELISPOT assay could benefit screening patients who may need more aggressive monitoring and management to overcome BKV infection.

We compared BKV-specific T cell responses between KTRs and HCs. Interestingly, KTRs showed significantly stronger T cell responses than the HCs irrespective of BKV infection status. BKV-specific T cell responses show enormous increase when BK virus is activated $[15,22]$. In $\mathrm{HCs}, \mathrm{BK}$ virus remained at latent infection state, but can reactivate in KTRs under immunosuppression [4]. Even though the no viremia group did not show overt BK virus infection, it is possible that immunosuppressant can activate BK virus at the subclinical level [30]. It can ex- 

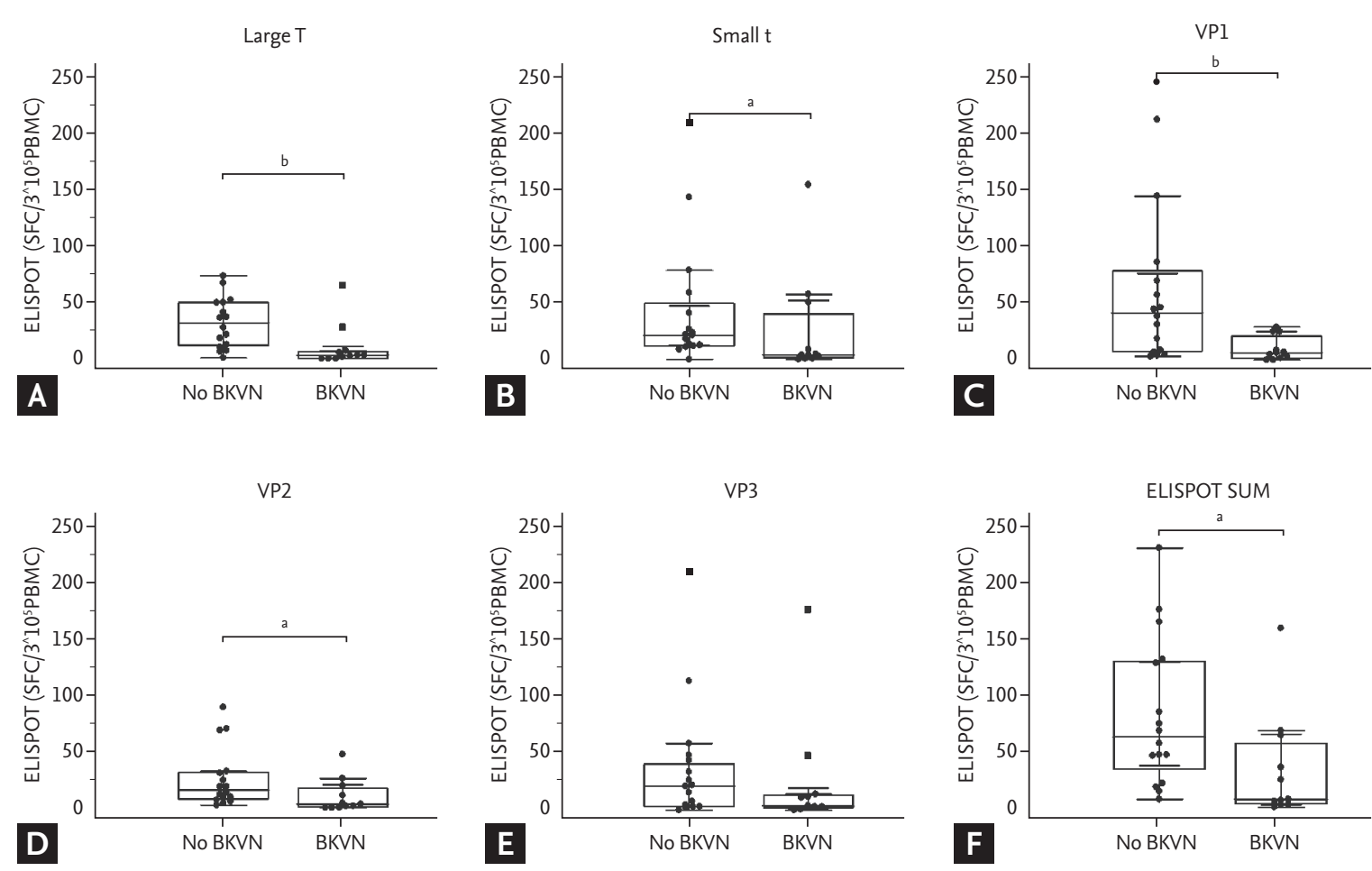

Figure 4. Comparison of T cell responses to five BK virus (BKV) antigens between kidney transplant recipients with BK virus-associated nephropathy (BKVN) and without BKVN in the BK viremia group. Vertical bars showed median value of BKV-specific enzyme-linked immunospot (ELISPOT) counts in each of the five BKV antigens. (A) In large T antigen, 11 BKVN patients had significantly lower spot counts than 16 no BKVN patients. (B) In small t antigen, BKVN patients had significantly lower spot number than no BKVN patients. (C) In VP1 antigen, BKVN patients had significantly fewer spots than BKVN patients. (D) In VP2 antigen, BKVN patients also had significantly fewer spots than no BKVN patients. (E) In VP3 antigen, BKVN patients had fewer spots than no BKVN patients, but not significant. (F) ELISPOT SUM shows the sum of ELISPOT counts of each of five BKV peptides (large tumor antigen [LT], St, VP1, VP2, and VP3). SFC, spot forming cell; PBMC, peripheral blood mononuclear cell. ${ }^{a} p<0.01{ }^{b} p<0.05$ by Mann-Whitney test.

plain the higher BKV-ELISPOT even in the no viremia group than HCs. In comparison among KTR groups with various BKV infection, ELISPOT results were highest in the cleared group. High ELISPOT can identify recovering BKV-specific immunity after BKV replication, hence it may suggest the strong BKV-specific immunity in this group. In contrast, decreased ELISPOT in the BK viremia group can represent their impaired BKV-specific immunity.

However, these results may be affected by confounding factors such as age, sex, HLA mismatch number, use of immunosuppressant and sampling time from kidney transplantation. First, HLA mismatch numbers were higher in the BK viremia group than cleared viremia group. Though the association of BK viremia with HLA mismatches is controversial, HLA mismatches can increase BKV infection because of impaired immuno- surveillance of BKV by virus-specific T cell responses in addition to higher immunosuppressant use and higher rate of rejection [23,31-34]. These differences can influence immunity against BKV, changing ELISPOT results. Seconds, time interval from transplantation to sampling were longer in the cleared viremia group than the BK viremia group ( 35.6 months vs. 11.1 months, $p<0.001$ ). In addition, compared to the cleared viremia group, serum tacrolimus level at the BKV-ELISPOT assays were higher in the BK viremia group $(p=0.005)$. So, different tacrolimus level with different sampling time could influence BKV-ELISPOT results.

Next, we investigated if the BKV-ELISPOT assay is effective in predicting clinical outcomes of BKV infection in terms of early clearance of BK viremia and BKVN development. Plasma BKV load > log 4 (10,000 copies $/ \mathrm{mL}$ ) is a reliable predictive marker of allograft 
damage by BKV [35-38]. Thus, KDIGO guidelines recommend reducing immunosuppressive medications when plasma BKV RT-qPCR level is persistently greater than $\log 4$ [39]. However, not all patients with high viremia showed unfavorable outcomes. For example, only $36.2 \%$ of $130 \mathrm{BK}$ viremia patients diagnosed in the first year showed persistent high viremia $(n=47)$ and incidence of histologically confirmed BKVN was $1.1 \%(\mathrm{n}=7)[38]$. In our previous study as well, only 33.3 $\%$ of renal allograft biopsies in KTRs with high BKV titer showed BKVN [24]. Thus, a uniform application of the recommendation, based only on plasma BKV RT-qPCR levels may induce unnecessary reduction of immunosuppressant, which can lead to increased risk of allograft rejection.

We postulate that the BKV-ELISPOT assay may be of benefit in discriminating severity or the prognosis of BKV infection in patients with high viral load. In fact, when we compared BKV-ELISPOT results between the controller and the noncontroller groups in the $\mathrm{BK}$ viremia group according to the clearance of $\mathrm{BKV}$ during follow-up, the spot counts for each of the five BKV antigens were lower in the noncontroller group. Also, BKV-ELISPOT results were significantly lower in KTRs who showed development of BKVN than in KT'Rs who did not show it. Interestingly, the peak level of blood BKV RT-qPCR titer and BKV-ELISPOT result had no significant correlation (Supplementary Table 1). It suggests that the BKV-ELISPOT assay may facilitate in predicting the clinical course of BKV infection independent of the BKV RT-qPCR titer.

There were some limitations in this study. First, retrospective cross-sectional analysis was conducted at a single center including relatively small number of patients. For this reason, there were confounding factors that could not be controlled. Seconds, this study did not include information of donor, such as BKV serostatus of donor and neutralizing antibodies against donor's strain. It is reported that donor neutralizing serostatus and genomic mismatch of neutralizing antibodies correlates with incidence of post-transplant BK viremia $[40,41]$. Thirds, cellular immunity before kidney transplant was not investigated in this study. One prospective study suggested that the decrease of ELISPOT results from pretransplantation to posttransplantation can help to predict of early-onset
BKV replication [21]. Finally, cut-off was not validated in this study. For clinical application, cut-off value should be investigated to stratify individual risk of BKV infection, guiding to adoption immunosuppressive strategy practically. Well-designed prospective studies controlling relevant factors are needed to use BKV-ELISPOT as a prognostic parameter for therapeutic intervention.

In conclusion, BKV-ELISPOT assay showed significant predictive value for the clinical course after BKV infection such as clearance of BK viremia and the development of BKVN. Thus, the application of BKV-ELISPOT assay in conjunction with blood BKV-DNA viral load may provide more accurate guidance for therapeutic intervention in KTRs with BKV infection.

\section{KEY MESSAGE}

1. BK virus-polymerase chain reaction (BKV PCR) currently used BKV infection monitoring method has limitation to predict clinical outcomes. BKV-enzyme-linked immunospot (ELISPOT) assays are high throughput method for monitoring BKV-specific cellular immunity.

2. BKV-ELISPOT results were higher in the cleared viremia group, the controller group and no BKVN (BK virus-associated nephropathy) group.

3. BKV-ELISPOT assay may predict clearance of $\mathrm{BK}$ virus and development of BKVN in kidney transplant recipients.

\section{Conflict of interest}

No potential conflict of interest relevant to this article was reported.

\section{Acknowledgments}

This research was supported by the National Research Foundation of Korea (NRF) grant funded by the Korea government (MSIP) (NRF-2017R1A2B4011181), Republic of Korea. And this study was also supported by the Basic Science Research Program through the National Research Foundation of Korea (NRF) funded by 
the Ministry of Education, Science, and Technology (NRF-2017R1DiAiBo3029140).

\section{REFERENCES}

1. Ramos E, Drachenberg CB, Portocarrero M, et al. BK virus nephropathy diagnosis and treatment: experience at the University of Maryland Renal Transplant Program. Clin Transpl 2002:143-153.

2. Brennan DC, Agha I, Bohl DL, et al. Incidence of BK with tacrolimus versus cyclosporine and impact of preemptive immunosuppression reduction. Am J Transplant 2005;5:582-594.

3. Park WY, Kang SS, Jin K, Park SB, Choe M, Han S. Longterm prognosis of BK virus-associated nephropathy in kidney transplant recipients. Kidney Res Clin Pract 2018;37:167-173.

4. Hirsch HH, Brennan DC, Drachenberg CB, et al. Polyomavirus-associated nephropathy in renal transplantation: interdisciplinary analyses and recommendations. Transplantation 2005;79:1277-1286.

5. Yi SG, Knight RJ, Lunsford KE. BK virus as a mediator of graft dysfunction following kidney transplantation. Curr Opin Organ Transplant 2017;22:320-327.

6. Vasudev B, Hariharan S, Hussain SA, Zhu YR, Bresnahan BA, Cohen EP. BK virus nephritis: risk factors, timing, and outcome in renal transplant recipients. Kidney Int 2005;68:1834-1839.

7. Kim YS. Open the black box: is urine valuable for screening BK virus-associated nephropathy? Kidney Res Clin Pract 2016;35:131-132.

8. Chon WJ, Aggarwal N, Kocherginsky M, Kane B, Sutor J, Josephson MA. High-level viruria as a screening tool for BK virus nephropathy in renal transplant recipients. Kidney Res Clin Pract 2016;35:176-181.

9. Sawinski D, Forde KA, Trofe-Clark J, et al. Persistent BK viremia does not increase intermediate-term graft loss but is associated with de novo donor-specific antibodies. J Am Soc Nephrol 2015;26:966-975.

10. Babel N, Fendt J, Karaivanov S, et al. Sustained BK viruria as an early marker for the development of BKV-associated nephropathy: analysis of 4128 urine and serum samples. Transplantation 2009;88:89-95.

11. Bonvoisin C, Weekers L, Xhignesse P, Grosch S, Milicevic M, Krzesinski JM. Polyomavirus in renal transplantation: a hot problem. Transplantation 2008;85(7 Suppl):S42-S48.

12. Nickel P, Bold G, Presber F, et al. High levels of CMV-IE1-specific memory $\mathrm{T}$ cells are associated with less alloimmunity and improved renal allograft function. Transpl Immunol 2009;20:238-242.

13. Lee SM, Kim YJ, Yoo KH, Sung KW, Koo HH, Kang ES. Clinical usefulness of monitoring cytomegalovirus-specific immunity by quantiferon-CMV in pediatric allogeneic hematopoietic stem cell transplantation recipients. Ann Lab Med 2017;37:277-281.

14. Lee H, Park KH, Ryu JH, et al. Cytomegalovirus (CMV) immune monitoring with ELISPOT and QuantiFERON-CMV assay in seropositive kidney transplant recipients. PLoS One 2017;12:eo189488.

15. Schachtner T, Muller K, Stein M, et al. BK virus-specific immunity kinetics: a predictor of recovery from polyomavirus BK-associated nephropathy. Am J Transplant 2011;11:2443-2452.

16. Binggeli S, Egli A, Schaub S, et al. Polyomavirus BK-specific cellular immune response to $\mathrm{VP}_{1}$ and large T-antigen in kidney transplant recipients. Am J Transplant 2007;7:1131-1139.

17. Egli A, Kohli S, Dickenmann M, Hirsch HH. Inhibition of polyomavirus BK-specific T-cell responses by immunosuppressive drugs. Transplantation 2009;88:1161-1168.

18. Leboeuf C, Wilk S, Achermann R, et al. BK polyomavirus-specific 9mer CD8 T cell responses correlate with clearance of BK viremia in kidney transplant recipients: first report from the Swiss transplant cohort study. Am J Transplant 2017;17:2591-2600.

19. Calarota SA, Aberle JH, Puchhammer-Stockl E, Baldanti F. Approaches for monitoring of non virus-specific and virus-specific T-cell response in solid organ transplantation and their clinical applications. J Clin Virol 2015;70:109-119.

20. Chakera A, Bennett S, Lawrence S, et al. Antigen-specific $\mathrm{T}$ cell responses to BK polyomavirus antigens identify functional anti-viral immunity and may help to guide immunosuppression following renal transplantation. Clin Exp Immunol 2011;165:401-409.

21. Schachtner T, Stein M, Babel N, Reinke P. The loss of BKV-specific immunity from pretransplantation to posttransplantation identifies kidney transplant recipients at increased risk of BKV replication. Am J Transplant 2015;15:2159-2169.

22. Schachtner T, Stein M, Sefrin A, Babel N, Reinke P. In- 
flammatory activation and recovering BKV-specific immunity correlate with self-limited BKV replication after renal transplantation. Transpl Int 2014;27:290-301.

23. Cioni M, Leboeuf C, Comoli P, Ginevri F, Hirsch HH. Characterization of immunodominant BK polyomavirus 9 mer epitope $\mathrm{T}$ cell responses. Am J Transplant 2016;16:1193-1206.

24. Chung BH, Hong YA, Kim HG, et al. Clinical usefulness of BK virus plasma quantitative PCR to prevent BK virus associated nephropathy. Transpl Int 2012;25:687-695.

25. Costa C, Bergallo M, Astegiano S, et al. Monitoring of BK virus replication in the first year following renal transplantation. Nephrol Dial Transplant 2008;23:3333-3336.

26. Schaenman JM, Korin Y, Sidwell T, et al. Increased frequency of BK virus-specific polyfunctional CD8+ T cells predict successful control of BK viremia after kidney transplantation. Transplantation 2017;101:1479-1487.

27. Hirsch HH, Randhawa P; AST Infectious Diseases Community of Practice. BK polyomavirus in solid organ transplantation. Am J Transplant 2013;13 Suppl 4:179-188.

28. Polz D, Stec A, Polz-Dacewicz M. BK-virus (BKV): structure, epidemiology and pathogenesis. J Pre-Clin Clin Res 2013;7:90-92.

29. Bechert CJ, Schnadig VJ, Payne DA, Dong J. Monitoring of BK viral load in renal allograft recipients by real-time PCR assays. Am J Clin Pathol 2010;133:242-250.

30. Hirsch HH. Polyomavirus BK nephropathy: a (re-)emerging complication in renal transplantation. Am J Transplant 2002;2:25-30.

31. Comoli P, Binggeli S, Ginevri F, Hirsch HH. Polyomavirus-associated nephropathy: update on BK virus-specific immunity. Transpl Infect Dis 2006;8:86-94.

32. El-Husseini A, Hassan W, Yaseen M, et al. Impact of human leukocyte antigen and calculated panel reactive antibody on BK viremia in kidney transplant recipients: a single-center experience and literature review. Transpl
Infect Dis 2019;21:e13071.

33. Awadalla Y, Randhawa P, Ruppert K, Zeevi A, Duquesnoy RJ. HLA mismatching increases the risk of BK virus nephropathy in renal transplant recipients. Am J Transplant 2004;4:1691-1696.

34. Hassig A, Roos M, Etter A, et al. Association of BK viremia with human leukocyte antigen mismatches and acute rejection, but not with type of calcineurin inhibitor. Transpl Infect Dis 2014;16:44-54.

35. Kim H, Yang WS, Han DJ, Park SK. Clinical courses of renal transplant recipients with high BK viremia. Transplant Proc 2013;45:2975-2979.

36. Randhawa $P$, Ho A, Shapiro R, et al. Correlates of quantitative measurement of BK polyomavirus (BKV) DNA with clinical course of BKV infection in renal transplant patients. J Clin Microbiol 2004;42:1176-1180.

37. Hasegawa M, Ito T, Saigo K, et al. Association of DNA amplification with progress of BK polyomavirus infection and nephropathy in renal transplant recipients. Transplant Pro 2014;46:556-559.

38. Elfadawy N, Flechner SM, Schold JD, et al. Transient versus persistent $\mathrm{BK}$ viremia and long-term outcomes after kidney and kidney-pancreas transplantation. Clin J Am Soc Nephrol 2014;9:553-561.

39. Kidney Disease: Improving Global Outcomes (KDIGO) Transplant Work Group. KDIGO clinical practice guideline for the care of kidney transplant recipients. Am J Transplant 2009;9 Suppl 3:S1-S155.

40. Abend JR, Changala M, Sathe A, et al. Correlation of BK virus neutralizing serostatus with the incidence of $\mathrm{BK}$ viremia in kidney transplant recipients. Transplantation 2017;101:1495-1505.

41. Solis M, Velay A, Porcher R, et al. Neutralizing antibody-mediated response and risk of BK virus-associated nephropathy. J Am Soc Nephrol 2018;29:326-334. 


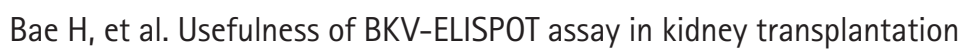

Supplementary Table 1. Correlation among T cell responses to BKV-specific antigens and peak level of BKV viral loads $(n=40)$

\begin{tabular}{lccccc}
\hline \multirow{2}{*}{ Spearman's correlation } & \multicolumn{5}{c}{ T cell response measured using ELISPOT } \\
\cline { 2 - 5 } & Large T & Small t & $\mathrm{VP}_{1}$ & $\mathrm{VP}_{2}$ & $\mathrm{VP}_{3}$ \\
\hline Peak plasma BKV-DNA PCR $(\mathrm{log})$ & & & & \\
$\quad$ Rho & -0.228 & -0.070 & -0.180 & -0.168 & 0.003 \\
$\quad$ value & 0.156 & 0.672 & 0.308 & 0.308 & 0.985 \\
\hline
\end{tabular}

BKV, BK virus; ELISPOT, enzyme-linked immunospot; PCR, polymerase chain reaction. 